\title{
El Niño and the Indian rainfall in June
}

\author{
Sulochana Gadgil ${ }^{1, *}$ and P. A. Francis ${ }^{2}$ \\ ${ }^{1}$ Centre for Atmospheric and Oceanic Sciences, Indian Institute of Science, Bengaluru 560012 , India \\ ${ }^{2}$ Indian National Centre for Ocean Information Services, Ministry of Earth Sciences, Hyderabad 500 090, India
}

We have addressed the question of whether the massive deficit of $42 \%$ in rainfall over the Indian region in June 2014 can be attributed primarily to the El Niño. We have shown that the variation of convection over the Northern part of the Tropical West Pacific (NWTP: 120-150E, 20-30N) plays a major role in determining the all-India rainfall in June with deficit (excess) in rainfall associated with enhancement (suppression) of convection over NWTP. In June 2014, the outgoing long wave radiation (OLR) anomaly over this region was unfavourable, whereas in June 2015, the OLR anomaly over NWTP was favourable and the all-India rainfall was $16 \%$ higher than the long-term average. We find that during El Niño, when the convection over the equatorial central Pacific intensifies, there is a high propensity for intensification of convection over NWTP. Thus, El Niño appears to have an impact on the rainfall over the Indian region via its impact on the convection over the West Pacific, particularly over NWTP. This occurred in June 2014, which suggests that the large deficit in June 2014, could be primarily attributed to the El Niño acting via intensification of convection over NWTP.

Keywords: All-India rainfall, El Niño, ENSO index, West pacific.

WE have known since the early eighties that there is a link between the interannual variation of the Indian rainfall during the summer monsoon (June-September) and El Niño and Southern Oscillation (ENSO) over the Pacific, with an increased propensity of droughts during the warm phase, El Niño, and of excess rainfall during the cold phase, La Niña ${ }^{1-3}$. A major characteristic of El Niño is a warm central equatorial Pacific, which is associated with organization of deep cumulonimbus clouds and plentiful rainfall over the region ${ }^{4-6}$. The variations of the Indian summer monsoon rainfall (ISMR) are most strongly linked to the variation of the sea surface temperature (SST) of the Niño 3.4 region $\left(5^{\circ} \mathrm{N}-5^{\circ} \mathrm{S}, 120^{\circ} \mathrm{E}-170^{\circ} \mathrm{W}\right)$ relative to that of the other Niño regions of the equatorial Pacific. In May 2014, the Niño 3.4 region was warmer than average and it was predicted that there was more than $65 \%$ chance for occurrence of El Niño during our summer monsoon season (June-September) ${ }^{7}$. Not surprisingly, the forecast issued by the India Meteorological

*For correspondence. (e-mail: sulugadgil@gmail.com)
Department in April 2014 indicated that the Indian summer monsoon rainfall (ISMR) in 2014 was likely to be less than the long-term average ${ }^{8}$, with a chance of almost one in four of it being a drought (generally defined as seasons with the deficit in the ISMR relative to the average, being more than one standard deviation). Almost all the dynamical models had predicted an increase in the magnitude of the warm SST anomaly of the Niño 3.4 region during the 2014 summer monsoon season ${ }^{7}$. However, the warm SST anomaly actually decreased considerably from June to July 2014, remained small in August and the El Niño appeared to have fizzled out in the middle of the monsoon season (Figure 1). Yet, the summer monsoon season of 2014 turned out to be a drought with a deficit in ISMR of 1.2 times the standard deviation (i.e. about $12 \%$ of the long-term average).

An important question to address is whether this drought can be attributed primarily to the El Niño, even though the El Niño did not develop as expected. It is important to address this question, because again in 2015, the equatorial central Pacific had been warm since April, with heavy clouding in the atmosphere above, and again almost all the models predicted an increase in the Niño 3.4 SST anomaly yielding a prediction of a $90 \%$ chance of the development of a full-fledged El Niño9. The El Niño was expected to play an important role and the India Meteorological Department ${ }^{10}$ in its forecast of 2 June (provided in Table 1 along with the forecast issued for the season of 2014) had suggested a $66 \%$ chance of a drought (i.e. more than four times the climatological probability), while the chance of normal rainfall was reduced from the climatological probability $33 \%$ to $7 \%$ ! In fact, it turned out to be a more severe drought than 2014, with a deficit in ISMR of 1.4 times the standard deviation (i.e. about $14 \%$ of the long-term average).

In investigating whether the drought of 2014 summer monsoon can be attributed to the El Niño, it should be noted that the deficit in the rainfall over the country as a whole varied a great deal from one month of the monsoon season to another. The all-India rainfall suffered a massive deficit of $42 \%$ of the average rainfall in June 2014 from which the monsoon did not recover. Relatively small deficit of around 10\% occurred in July and August, while in September the intense rainfall event in Jammu and Kashmir (leading to unprecedented floods) and heavy rains in the northwest led to the Indian rainfall being higher than average by $8 \%$ (Figure 2). Thus, it is 


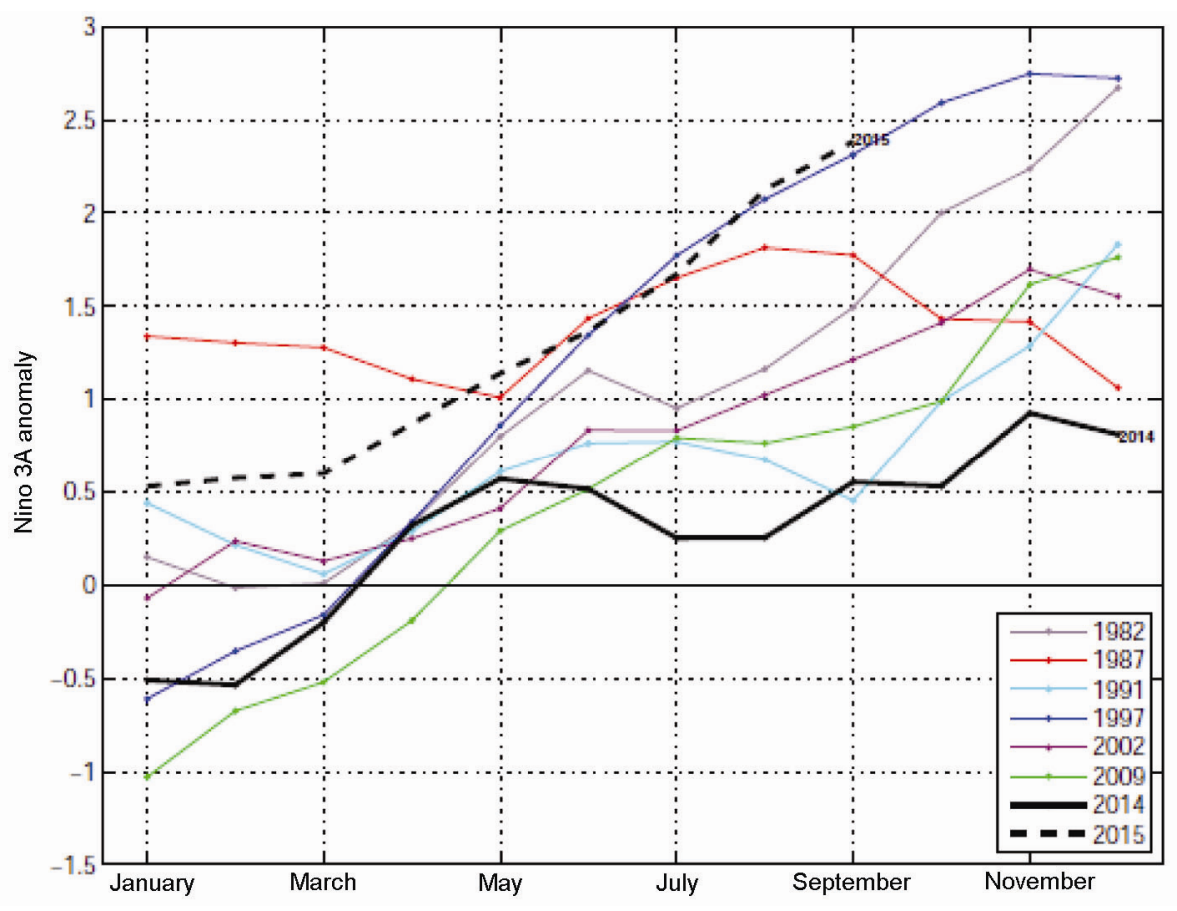

Figure 1. Variation of the Niño 3.4 SST anomaly for 2014, 2015 and several El Niño years.

Table 1. Long range prediction of ISMR as probabilities of different ranges of rainfall issued by IMD for 2014 and 2015. Climatological probabilities of the different ranges of rainfall are also given

\begin{tabular}{lcccc}
\hline Category & $\begin{array}{c}\text { Rainfall range } \\
(\% \text { of LPA) }\end{array}$ & $\begin{array}{c}\text { Climatological } \\
\text { probability (\%) }\end{array}$ & $\begin{array}{c}\text { 2014: Forecast } \\
\text { probability (\%) }\end{array}$ & $\begin{array}{c}\text { 2015: Forecast } \\
\text { probability (\%) }\end{array}$ \\
\hline Deficient & $<90$ & 16 & 33 & 66 \\
Below normal & $90-96$ & 17 & 38 & 27 \\
Normal & $96-104$ & 33 & 26 & 7 \\
Above normal & $104-110$ & 16 & 3 & 0 \\
Excess & $>110$ & 17 & 0 & 0 \\
\hline
\end{tabular}

important to also investigate the monsoon and El Niño links on the monthly scale and in particular whether the large deficit of $42 \%$ in June can be attributed to the occurrence of the El Niño.

The observed interannual variation of the all-India rainfall in June during 1982-2015 is shown in Figure 3. It is seen that in this period, the lowest rainfall in June occurred in 2009 while 2014 is the year with the second lowest rainfall. It has been shown that the exceptionally large deficit in the rainfall in June 2009 was associated with the unusual situation of the Bay of Bengal being cooler than the eastern equatorial Indian Ocean ${ }^{11,12}$. Note that the last 4 years have witnessed particularly large interannual variation of June rainfall with a large deficit in 2012 (which incidentally was not unexpected since an El Niño was predicted for 2012 as well), followed by a large excess in 2013, a very large deficit in 2014 and a substantive excess in 2015.

In this article, we first attempt to understand the interannual variation of the June rainfall over the Indian region and identify the factors which play an important role in determining this variation. We analyse the link between the monsoon rainfall over the Indian region and ENSO and address the problem of whether the anomalous behaviour of the monsoon in June 2014 can be attributed primarily to the El Niño. It is interesting that during June of 2015 the Niño 3.4 region was very warm, warmer than in June 2014 (Figure 1). Yet, the Indian rainfall was 16\% in excess of the long-term average. We also address the question of whether the impact of the El Niño of 2015 on the June rainfall was not as adverse or the adverse impact was mitigated by a favourable impact of some other factor.

\section{Background}

It should be noted that, in addition to ENSO, the equatorial Indian Ocean Oscillation (EQUINOO) also plays an important role in the interannual variation of the Indian summer monsoon rainfall ${ }^{13,14}$. EQUINOO involves an oscillation between a positive phase characterized by 

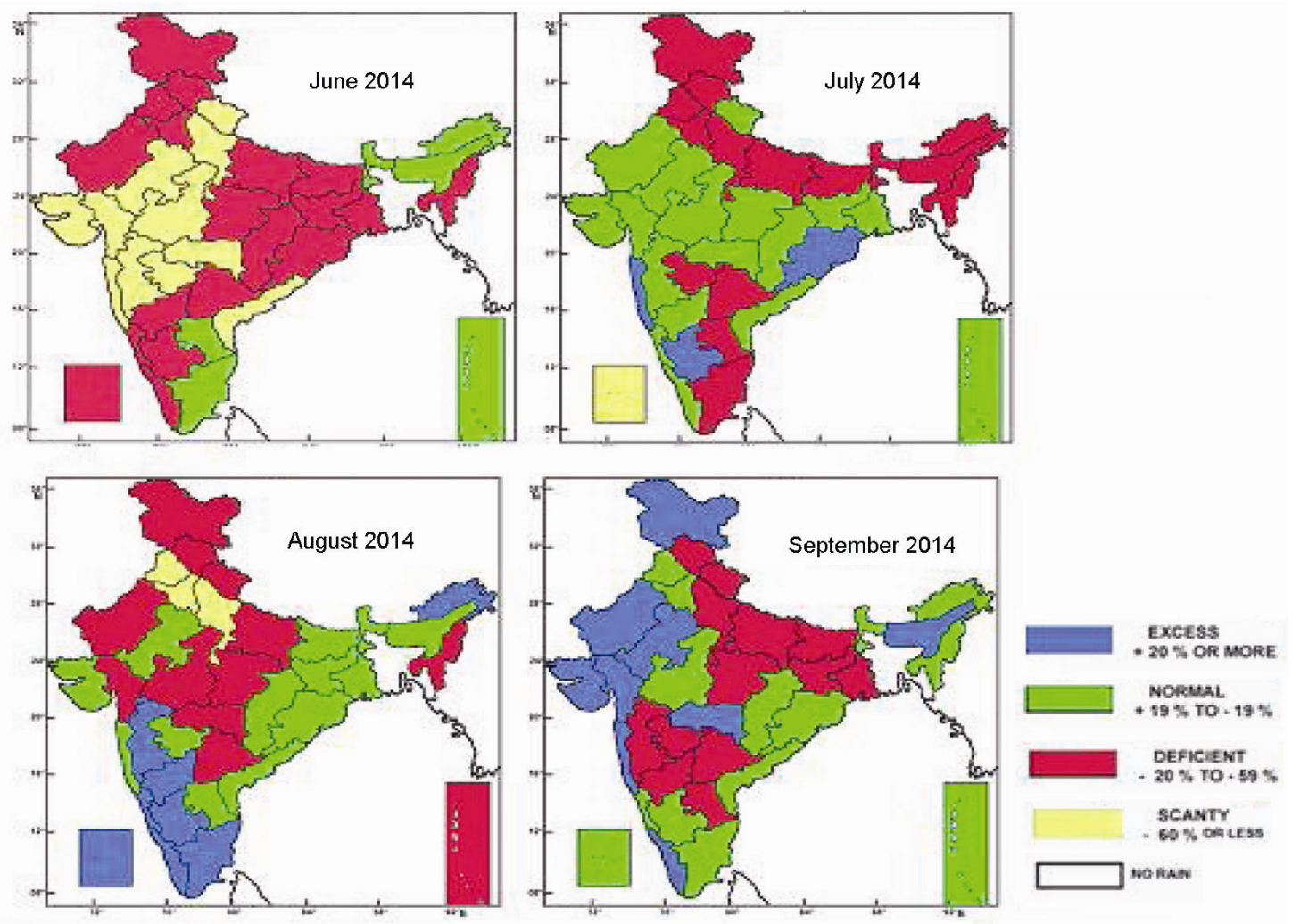

Figure 2. Monthly mean rainfall anomaly maps from IMD report: Monsoon 2014 (ref. 36).

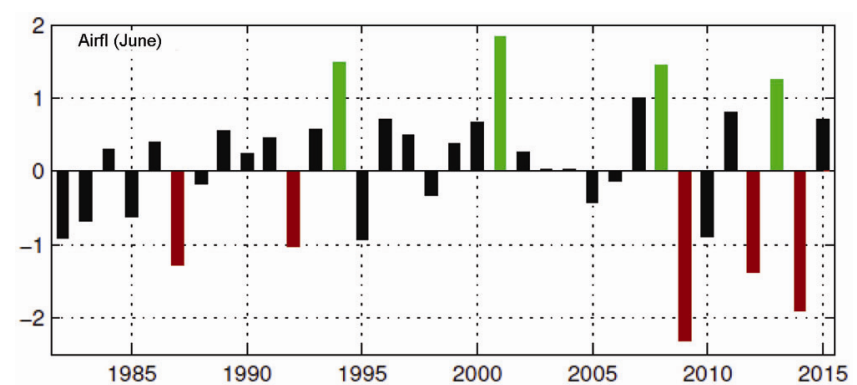

Figure 3. Variation of the anomaly of all-India rainfall in June, normalized by the standard deviation.

enhanced convection over the western equatorial Indian Ocean and suppressed convection over the eastern equatorial Indian Ocean, which is favourable for monsoon rainfall over the Indian region and a negative phase with opposite signs of convection anomalies over these regions, which is unfavourable for the Indian monsoon. On the monthly/bimonthly scales also, the correlation of the Indian rainfall with indices of EQUINOO and ENSO is comparable ${ }^{15}$.

Rainfall over the Indian region during the summer monsoon season is linked to the convection/precipitation over the equatorial Indian Ocean because northward propagations of cloud systems generated over this warm ocean onto the Indian region, play an important role in sustaining the large-scale monsoon rainfall over the
Indian landmass. Westward propagation of synoptic systems from the Bay of Bengal, which is often a result of westward propagation of systems from the West Pacific, also makes a substantial contribution to the summer monsoon rainfall over the Indian region. Hence, in addition to the link with convection/rainfall over the equatorial Indian Ocean, we expect the variation of the summer monsoon rainfall over the Indian region to be related to the variation of convection over the West Pacific. Such links would be manifested in the links to the rainfall over southeast Asia, parts of China and Japan and earlier studies have focused on the relationship of the variation of the rainfall over the Indian region with that over these Asian countries. It has been shown that the variation of the rainfall in June and July over central India is out of phase with the Beiyu rainfall over the Japanese archipelago ${ }^{16}$. Interannual variation of the summer monsoon rainfall over South Asia is found to be in phase with the rainfall variations over north China and out of phase with rainfall variations over southern Japan ${ }^{17}$. Now, with an adequate sample of the satellite-derived outgoing longwave radiation available, it is possible to directly investigate the relationship of the monsoon rainfall with convection over the West Pacific.

In the month of June, which is our focus here, the major rain-belt extends from the Indian longitudes eastward to about $140^{\circ} \mathrm{E}$ over the West Pacific; and even on a single day, the deep clouds are often organized as a coherent 
band stretching from the Indian longitudes to the West Pacific. Hence, we expect the variation of the June rainfall over the Indian region to be related to the variation of convection over the West Pacific as well as the equatorial Indian Ocean. June is the month in which the spring to summer transition takes place, while July and August are peak months of the Indian summer monsoon. The important events in June are as follows. Onset of the monsoon over Kerala heralding the arrival of the tropical convergence zone (TCZ) from the equatorial Indian Ocean onto the southern part of the Indian peninsula, occurring towards the beginning of the month. Advance of the monsoon which leads to the establishment of the TCZ over the Indian monsoon zone around the end of the month ${ }^{18}$. The advance of the monsoon is associated with northward propagation of the TCZ across the Indian region and westward propagation of synoptic systems from the Bay of Bengal ${ }^{19}$. Many of the systems over the Bay of Bengal arise due to westward propagation of systems from the West Pacific ${ }^{20}$. Often the northward advance is achieved by more than one northward propagation with the monsoon activity weakening after an advance through about $500 \mathrm{~km}$ and a fresh surge taking the forward edge of monsoon rains to move further northward ${ }^{21}$. Such phases of 'hiatus' in the progression of the monsoon which lead to prolonging of the advance phase occurred in the onset phase of the monsoon season of 2014 but not in 2015 . There is considerable interannual variation in the date of onset over Kerala ${ }^{22}$ as well as the duration of the advance phase $^{23}$. While the total all-India rainfall in June is not significantly correlated with the date of onset over $\mathrm{Kerala}^{24}$, the variation in period of the advance has contributed to the major deficit in June 2002 and 2009 (refs 11, 23). However, here we attempt to identify the factors that lead to the variation of the total all-India rainfall in June, without going into details about the contributions of the anomalies in the duration of the advance phase to the anomalies of the June rainfall.

\section{Data}

In this study, we use the outgoing longwave radiation (OLR) measured by the NOAA satellites, archived at http://www.cdc.noaa.gov (Liebmann and Smith $^{25}$ ) as a proxy for tropical precipitation. We use an ENSO index which is defined as the negative of the normalized SST anomaly of the (Niño 3.4, region obtained from http:// www.cpc.noaa.gov). This definition implies that positive values of the index are favourable for the monsoon. Monthly mean all-India rainfall is obtained from Indian Institute of Tropical Meteorology (IITM, http://tropmet. res.in), Pune. Data on the geopotential height and zonal and meridional components of wind at $300 \mathrm{hPa}$ are taken from NCEP Reanalysis (Kalnay et al. ${ }^{26}$; http://www.cdc. noaa.gov).

\section{Interannual variation of the June rainfall over the Indian region}

The nature of the teleconnections of the all-India rainfall (AIRFL) in June with the convection over different parts of the Indo-Pacific region can be gleaned from Figure $4 a$ in which the spatial variation of the correlation coefficient between the June rainfall and OLR is shown. It is seen that the relationship of the June rainfall with convection over the Indo-Pacific region, is the strongest with the convection over the Northern West Tropical Pacific (NWPC: $120-150^{\circ} \mathrm{E}, 20-30^{\circ} \mathrm{N}$ ), with deficit in June rainfall associated with enhanced convection (i.e. negative OLR anomaly) over NWTP. There is also a significant negative correlation with the convection over the southern part of the eastern equatorial Indian Ocean (SEEIO: $\left.85-105^{\circ} \mathrm{E}, 15^{\circ} \mathrm{S}-5^{\circ} \mathrm{S}\right)$.

The relationship of the AIRFL in June with the OLR of NWTP is rather strong (Figure $4 b$ ) and it explains about $32 \%$ of the variance of the AIRFL. The relationship of AIRFL with the OLR of SSEIO is not so strong (Figure $4 c$ ); explaining a little over $14 \%$ of the ISMR variance. It is seen that for the deficit in June 2014, the convection increased over NWTP as well as SEEIO. On the other hand, for June 2015 with rainfall in excess of the normal, convection over both the critical regions was suppressed. In June 2012 (2013), the OLR anomaly over NWTP was unfavourable (favourable) and deficit (above normal rainfall) occurred despite a favourable (an unfavourable) anomaly over SEEIO. The correlation coefficient of OLR over NWTP with the OLR over SEEIO is 0.24 which is significant at $90 \%$, but small. Hence, the signs of the OLR anomalies over the two regions are opposite in almost 50\% cases (as in 2012 and 2013). Thus, if the contribution of the variation of OLR over SEEIO to the variation of June rainfall is also considered, we expect more variance to be explained than that by the variation of NWTP alone.

In fact, there is a large overlap between SEEIO and the eastern pole of EQUINOO, i.e. EEIO $\left(90-110^{\circ} \mathrm{E}, 10^{\circ} \mathrm{S}-\right.$ EQ) and the OLR of SEEIO is highly correlated with that of EEIO (correlation coefficient of 0.87 ). The variation of convection of SEEIO can thus be considered to be a manifestation of the variation of EQUINOO. We attempt to understand next the variation of convection over the NWTP which appears to play a critical role in the variation of AIRFL in June.

\section{Link of June rainfall with the West Pacific}

For understanding the variation of convection over the NWTP, it is necessary to elucidate the nature of the system with which the convection is associated. The variation of the monthly average precipitation over the West Pacific longitudes of $120-150^{\circ} \mathrm{E}$ is shown along with that 

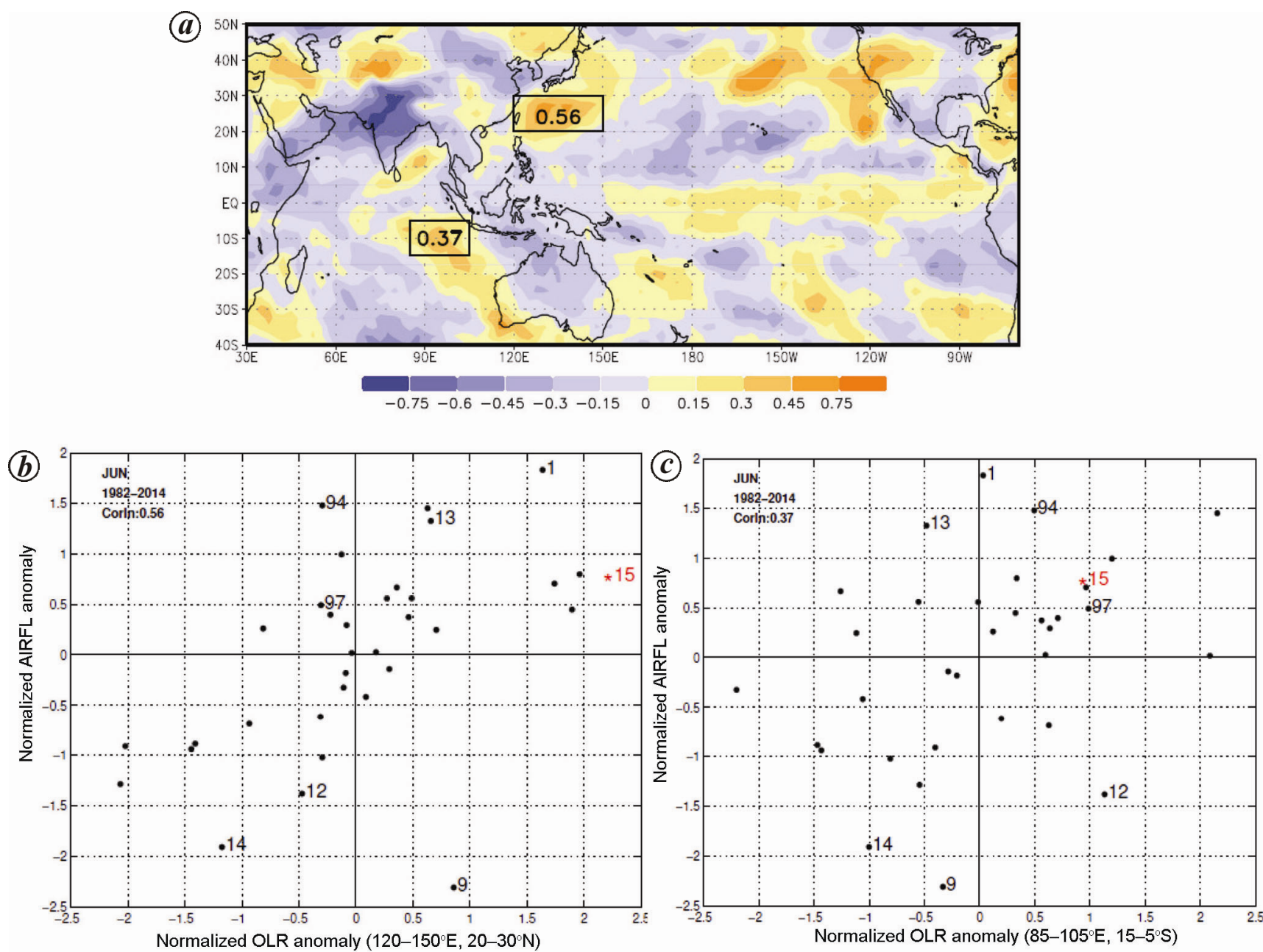

Figure 4. $\boldsymbol{a}$, Spatial pattern of the correlation coefficient between all-India June rainfall and OLR. The black boxes indicate regions of high magnitude of correlation, the number within each box, the correlation coefficient for the OLR averaged over the box. $\boldsymbol{b}$, All-India rainfall (AIRFL) anomaly normalized by standard deviation for the month of June is plotted against the OLR over the NWTP $\left(120-150^{\circ} \mathrm{E}, 20-30^{\circ} \mathrm{N}\right)$, normalized by standard deviation for June. Correlation coefficient for 1982-2014 is also shown. $c$, All-India rainfall (AIRFL) anomaly normalized by standard deviation for June is plotted against the OLR anomaly over the SEEIO $\left(85-105^{\circ} \mathrm{E}, 15-5^{\circ} \mathrm{S}\right)$, nomalized by standard deviation for June. Correlation coefficient for 1982-2014 is also shown.

over the Indian longitudes $\left(70-90^{\circ} \mathrm{E}\right)$ in Figure 5. It is seen that the seasonal migration of the rain-belt associated with the TCZ over the West Pacific is somewhat different from that over the Indian longitudes. Over the Indian longitudes, the migration of the TCZ culminates further northward and this northern most latitude is attained about one month earlier relative to that over the West Pacific. In both cases, on the monthly scale, the rainbelt extends from south of the equator to this northernmost latitude, which is a manifestation of the fluctuations in the location of the TCZ over this latitudinal range on the subseasonal scale. As over the Indian longitudes, northward propagation of the rainbelts/low OLR zones emanating from the equatorial regions are seen over the West Pacific throughout the monsoon season (e.g. Figure $6 a$ ). It is well-known that northward moving cyclones over the West Pacific are associated with deficit rainfall over the Indian region ${ }^{27}$. However, we find that the major contribution to the variation of convection over the West
Pacific during May-June arises from the variation of organized convection on larger spatial scales than the synoptic scales.

Another difference in the two regions is that the subtropical band north of $30^{\circ} \mathrm{N}$ is stronger over the West Pacific than over the Indian longitudes. This is also seen in the difference in the June rainfall over the two regions (Figure 5). An important question to address is whether the enhancement of convection over NWTP in June occurs in association with the southward movement/ extension of the subtropical band or farther culmination of the northward propagation.

Daily variation of the mean OLR at the central longitude of $130^{\circ} \mathrm{E}$ of NWTP is shown along with the variation for 2 years with very low OLR over NWTP in June (1982 and 1987) and one with high OLR over NWTP in June (1991) in Figure $6 a$. It is seen that climatologically, the low OLR belt migrates southward to occur over NWTP during mid-May to mid-June. The anomalies of 
precipitation and the zonal wind and geopotential height of $300 \mathrm{hPa}$ for 1987 and 1991 are shown in Figure $6 b$. Southward migration of the subtropical jet stream is clearly seen in 1987, whereas in 1991, eastward anomalies occur over the NWTP. Examination of the other cases of high and low convection over NWTP also clearly shows that the enhancement of convection over NWTP is associated with southward migration/extension of the subtropical jet (e.g. satellite image for 17 June 2014 depicted in Figure 7).

We next consider the links of the convection over the NWTP with the Asian summer monsoon, since the tropical West Pacific comes under its sway in the summer. The Asian summer monsoon consists of three major regional components: the Indian Summer Monsoon, East Asian Summer/subtropical monsoon (EASM) and Western North Pacific Summer Monsoon (WNPSM) ${ }^{28-30}$. While the WNPSM and the Indian summer monsoon are tropical monsoons characterized by TCZs with southwesterlies on the equatorward side and northward crossequatorial flows, the EASM is characterized by a lowlevel convergence zone between southerlies from the tropics and weak northerlies from the mid-latitudes. There is a large overlap between the zone of the EASM, which is considered to be a subtropical monsoon

Time-latitude section of precipitation climatology (CMAP)
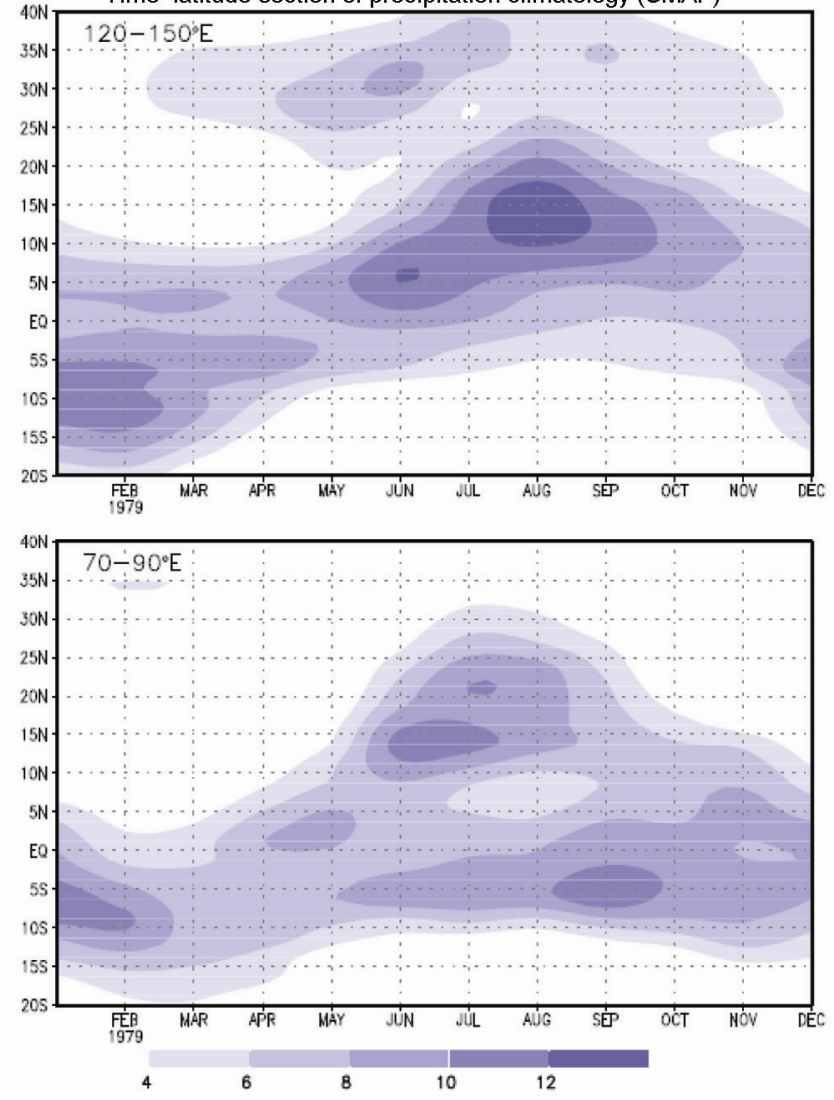

Figure 5. Time-latitude section of the mean monthly precipitation $\left(\mathrm{mm} \mathrm{day}{ }^{-1}\right)$ averaged over $120-150^{\circ} \mathrm{E}$ (top) and $70-90^{\circ} \mathrm{E}$ (bottom). encompassing eastern China, Japan, and Korea $\left(20-45^{\circ} \mathrm{N}\right.$, $100-140^{\circ} \mathrm{E}$ ) and the region NWTP critical for June rainfall over India. The maximum rainfall over South China (SC), the region south of $28^{\circ} \mathrm{N}$ and east of $110^{\circ} \mathrm{E}$, occurs in May-June, in association with the east Asian subtropical monsoon frontal zone. An enhancement of the rainfall over South China generally occurs with an enhancement of the entire Meiyu/Baiu frontal rainfall, stretching from $\mathrm{SC}$ to south of Japan. The spatial pattern of leading mode (EOF 1) of May-June precipitation over East Asia shows a coherent band over $20-30^{\circ} \mathrm{N}$ stretching eastward from South China to $140^{\circ} \mathrm{E}$ and beyond $\mathrm{d}^{31}$. We, therefore, expect the variation of convection over NWTP to be linked to the important weather events of EASM. In spring, the western Pacific subtropical ridge extends deeply into Indochina via the northern South China Sea, and cold fronts migrate southward from north of about $50^{\circ} \mathrm{N}$ to around $35^{\circ} \mathrm{N}$. This is clearly seen in the daily variation of the low OLR belt along the central longitude of $130^{\circ} \mathrm{E}$ for 1985 , 1986, 1987 shown in Figure 8, in which the periods of occurrence of the pre-meiyu and meiyu events identified by Ho and Wang ${ }^{32}$ are also shown. With the establishment of a convection zone in the form of stationary front (pre-mei-yu front), the low-level southwesterly flow from the Indochina peninsula manages to interact with the subtropical weather systems along the East Asian coast. Boosted by the warm and moist low-level southwesterly, the front embeds many mesoscale convection cells ${ }^{33}$, which brings a short rainy season, which is called the premeiyu (preflood or presummer) period ${ }^{34}$. The brief premeiyu period is associated with the stationary front around $25^{\circ} \mathrm{N}$, which then jumps to $35^{\circ} \mathrm{N}$ in the meiyu position.

It is seen that southward movement of the subtropical front leads to enhancement of convection over NWTP which persists in the pre-meiyu phase and terminates with the commencement of the meiyu phase. Northward moving bands from the tropics (associated with the TCZ) are also seen to culminate over NWTP just before the commencement of the pre-meiyu period in 1986 and 1987. It is known that in $15 \%$ of the years, the pre-meiyu period was delayed, and in some years there is not much trace of a pre-meiyu front. We expect this variation in the intensity and duration of the pre-meiyu rainy season to be reflected in the variation in convection and rainfall over the NWTP and hence of the June rainfall over the Indian region. This relationship needs to be investigated further.

The nature of relationship of the variation of convection over NWTP to convection over the Indo-Pacific region can be gleaned from Figure 9 in which the spatial variation of the correlation of the OLR with the OLR over NWTP is depicted. It is seen that the variation of OLR over NWTP is poorly correlated with that over the equatorial Indian Ocean. Over the Pacific, in the same latitudinal belt, it is negatively correlated with the region to the east between about $150^{\circ} \mathrm{E}$ and $140^{\circ} \mathrm{W}$ and positively 
(a)
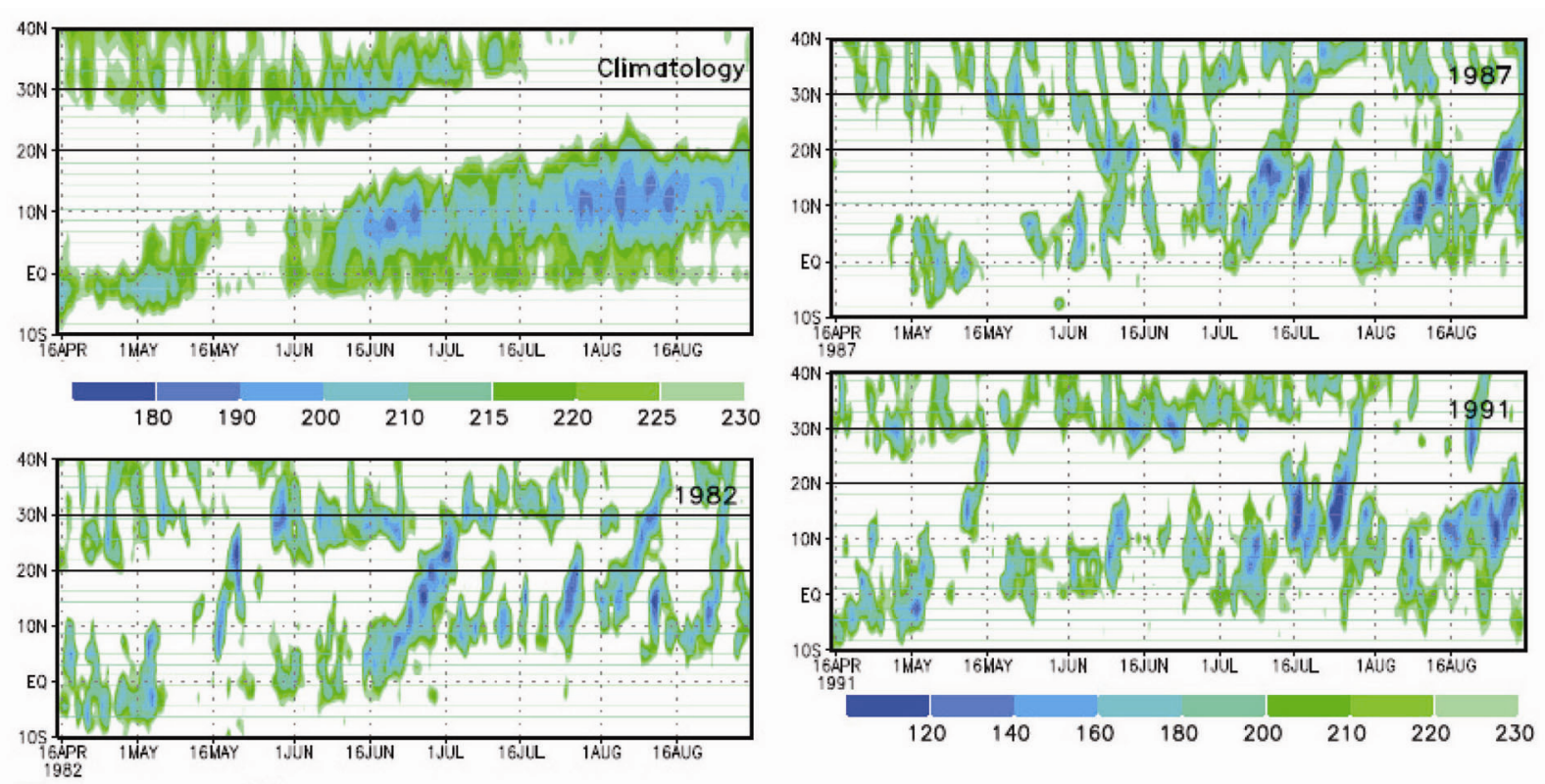

(b)

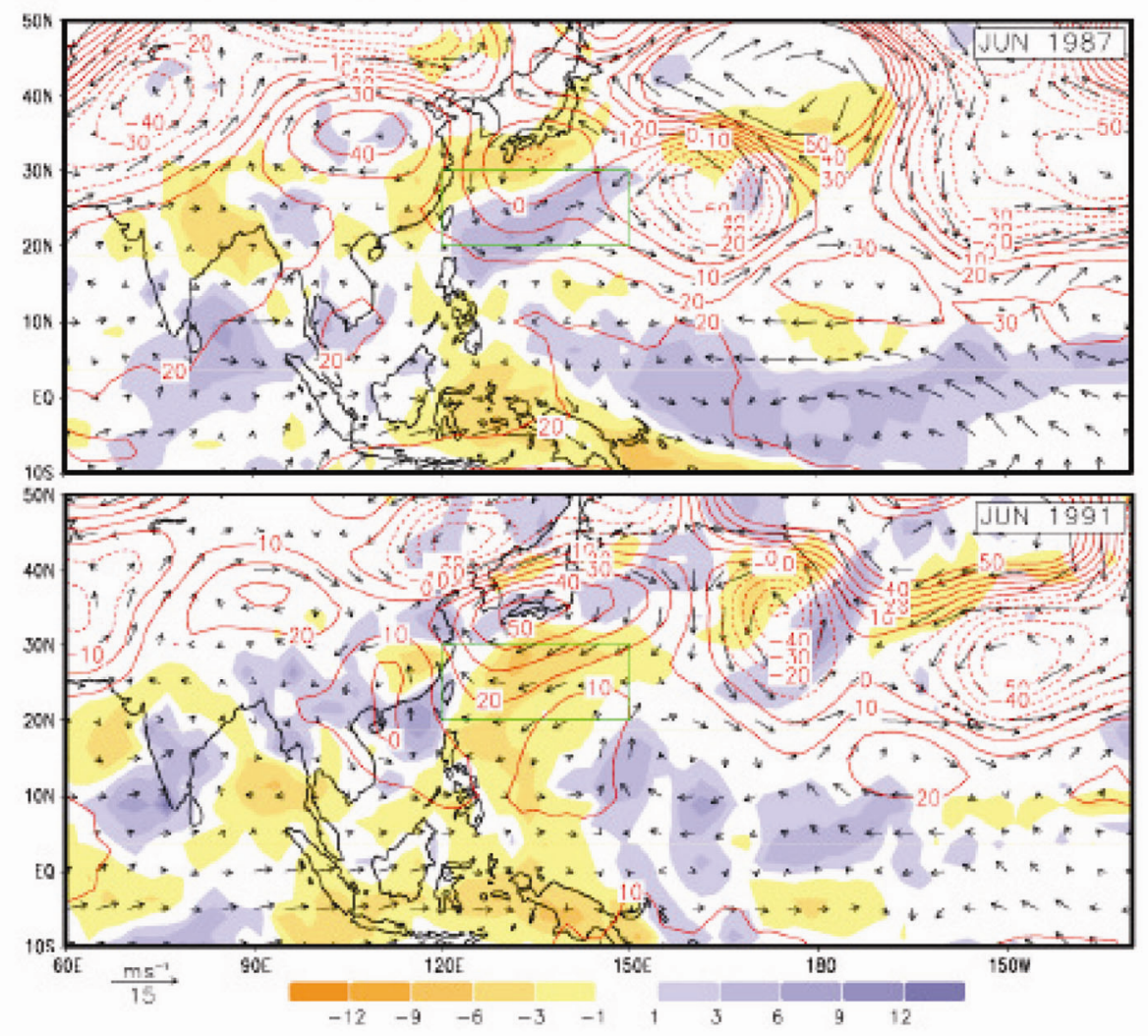

Figure 6. $\boldsymbol{a}$, Daily variation of low OLR belts at $130^{\circ} \mathrm{E}$ in 1982,1987 and 1991 . Climatological variation is shown in the top, left panel. $\boldsymbol{b}$, Anomalies of precipitation $\left(\mathrm{mm} \mathrm{day}^{-1}\right)$ and wind and geopotential height anomalies at $(300 \mathrm{hPa})$ and precipitation anomaly in June 1987 (top) and June 1991 (bottom).

correlated to the region farther east. This wave-like pattern could be a manifestation of Rossby waves in the subtropical jet. In addition, the OLR over NWTP is positively correlated to the OLR over central and eastern equatorial Pacific, a region which is associated with large variation in OLR in association with ENSO.

\section{Link of June rainfall over the Indian region with El Niño}

It is well-known that on the seasonal scale, there is a strong relationship between the ISMR and ENSO. For the period 1982-2014 considered here, the correlation 


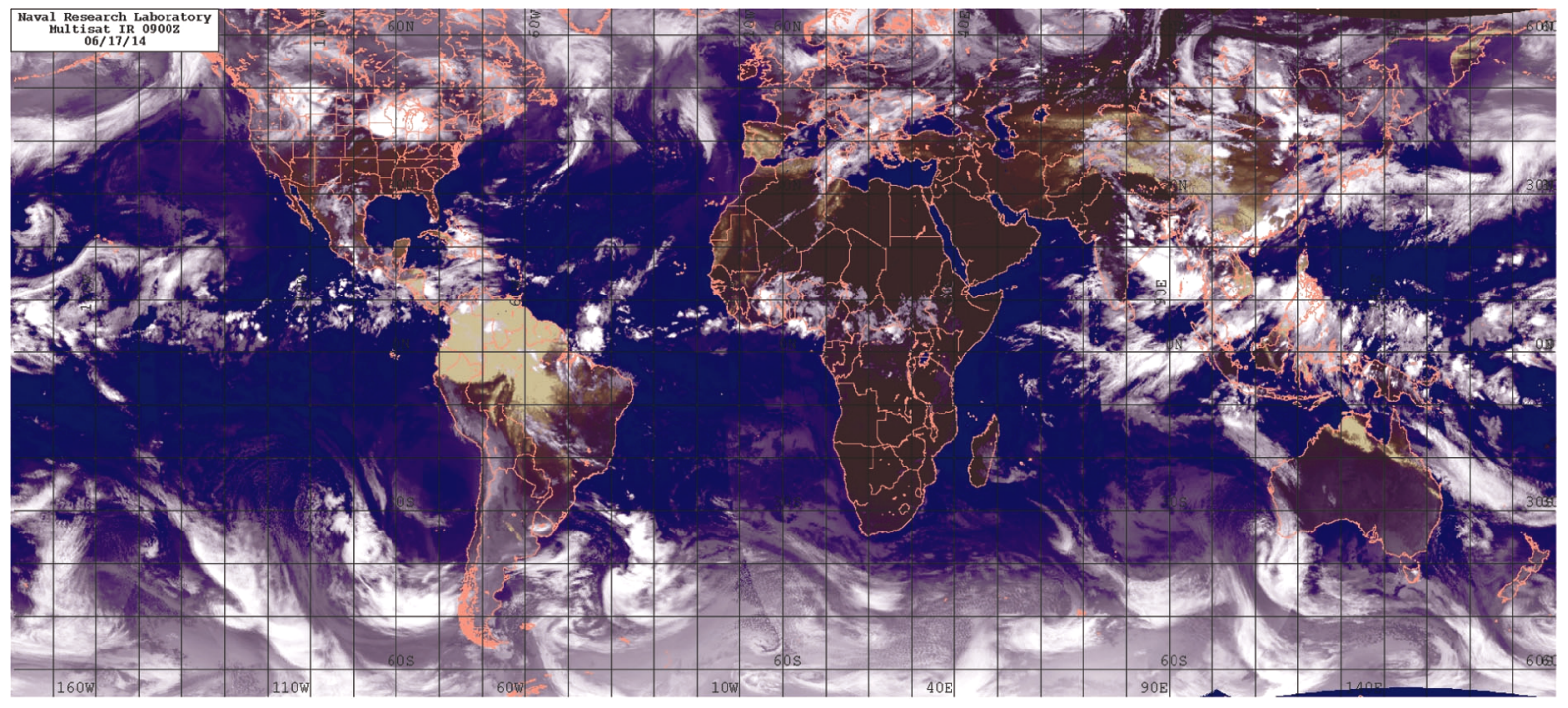

Figure 7. Infrared satellite image for 17 June 2014.

coefficient between ISMR and the seasonal ENSO index is 0.44 , i.e. the relationship explains about $20 \%$ of the variance of the monsoon rainfall. The variation of the AIRFL for June with the ENSO index is depicted in Figure $10 a$. It is seen that all the years with deficit of larger than one standard deviation (i.e. June droughts) are characterized by an unfavourable ENSO index, i.e. negative values of ENSO index. However, the range of variation of June AIRFL for negative ENSO values is rather large. Thus, while the strong El Niño event of 1987 is associated with a drought, the rainfall was well above normal for almost equally strong El Niño events of 1997 and 2015. Similarly for comparable values of the ENSO index, the anomaly of the June AIRFL in 1994 was large and positive while that in June 2012 was almost as large and negative. These differences can be attributed to EQUINOO which was strong and positive in 1994 and 1997 and positive in 2015 as well (Figure $4 c$ ). This large variation in the range of rainfall, particularly for negative values of ENSO index, leads to a poor correlation coefficient of 0.24 which is still significant at $90 \%$.

The convection pattern associated with ENSO in June, is revealed by the spatial variation of the correlation of the ENSO index with OLR over the Indo-Pacific region (Figure $10 b$ ). Note the high correlation with convection over the equatorial central Pacific, which is a distinguishing attribute of ENSO. In addition, the suppression of convection over the western equatorial Pacific and parts of the eastern equatorial Indian Ocean, which is a wellknown feature of El Niño, is also clearly seen in Figure $10 \mathrm{~b}$. It is interesting that there is a significant correlation between ENSO index and the OLR of NWTP as well.

As pointed out earlier, the correlation of AIR in June with the OLR of NWTP is very high (Figure $4 a$ ). It is important to note that the correlation of June AIRFL with the convection over central and western equatorial Pacific (for which the ENSO signature is prominent) is rather small (Figures $4 a$ and $10 b$ ). The ENSO signature over the eastern equatorial Indian Ocean is characterized by suppression of convection, implying a favourable OLR anomaly over the eastern part of SEEIO. However, the correlation of the OLR over SEEIO with the ENSO index is poor (correlation coefficient -0.04).

We find that the relationship of the variation of the convection over NWTP in June with the ENSO index during 1982-2014 is not strong with correlation coefficient of 0.28 ; and the teleconnection via the atmospheric bridge with the convection over the equatorial central Pacific is even weaker (Figure 11). However, if cases in which there is convection over the equatorial central Pacific (OLR $<240 \mathrm{Wm}^{-2}$ ) are considered, convection occurs over NWTP in 7 out of 9 years. Thus, there is a high propensity of convection over NWTP in El Niño years. This intensification of convection over NWTP occurs with the southward migration of the subtropical jet. Thus, our observations suggest that the impact of the El Niño on the monsoon rainfall in June is via the impact on the west Pacific. Given the intense convection over NWTP in June 2014, we may conclude that the El Niño contributed in a major way to the deficit rainfall of June 2014.

Shaman and Tziperman ${ }^{35}$ showed that the impact of enhanced convection over the equatorial Pacific associated with El Niño is an increase in the vorticity anomalies within the North African-Asian (NAA) jet. Their results indicate that westward propagating anomalies in both the tropics and middle latitudes produce the anomaly response within the NAA jet. They suggest that the teleconnection linking ENSO and the monsoons is mediated by the response of the NAA jet to 

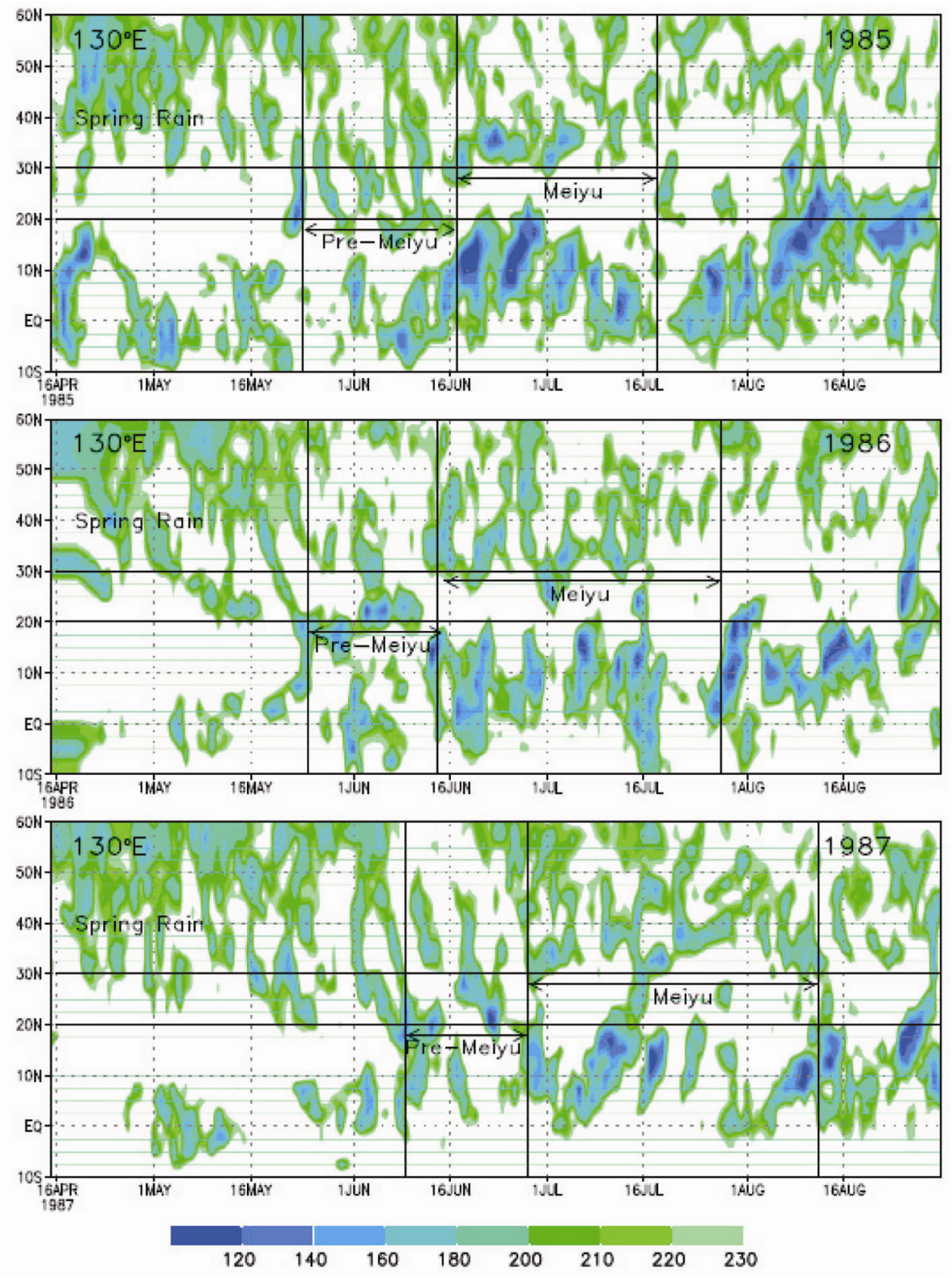

Figure 8. Daily variation of low OLR belts at $130^{\circ} \mathrm{E}$ during 16 April-31 August 1985, 1986 and 1987. Periods of pre-meiyu and meiyu from Ho and Wang ${ }^{32}$ are also marked.

westward propagating Rossby waves. Our observations of the association of El Niño events with enhanced convection and southward migration of the subtropical jet to the NWTP region (which in turn is associated with deficit in June rainfall over the Indian region), support their results from a simple barotropic model. However, the link of the AIRFL in June to El Niño via convection anomalies over NWTP has to be tested with more realistic, state-of-theart general circulation models. Also, it is important to derive the impact of enhanced heat source over the equatorial West Pacific (i.e. absence of convection over the equatorial central Pacific) on the subtropical jet to check whether there is high propensity of the jet remaining north of NWTP in June.
It is important to note that not all the El Niño events in June are associated with enhancement of convection over NWTP. In particular, in June 2015, the convection was suppressed over most of NWTP despite a large magnitude of the ENSO index. Also, such convection anomalies do sometimes occur in the absence of an El Niño as in the cases of 1995 and 2010 (Figure 11). Thus, while the occurrence of the El Niño is an important factor in determining convection over the region NWTP, other factors, perhaps arising from mid-latitude dynamics, also play a role in determining the variation of convection over NWTP. When the entire variation of the ENSO index is considered (rather than focusing only on El Niño), the pattern of variation of the OLR over the West Pacific 


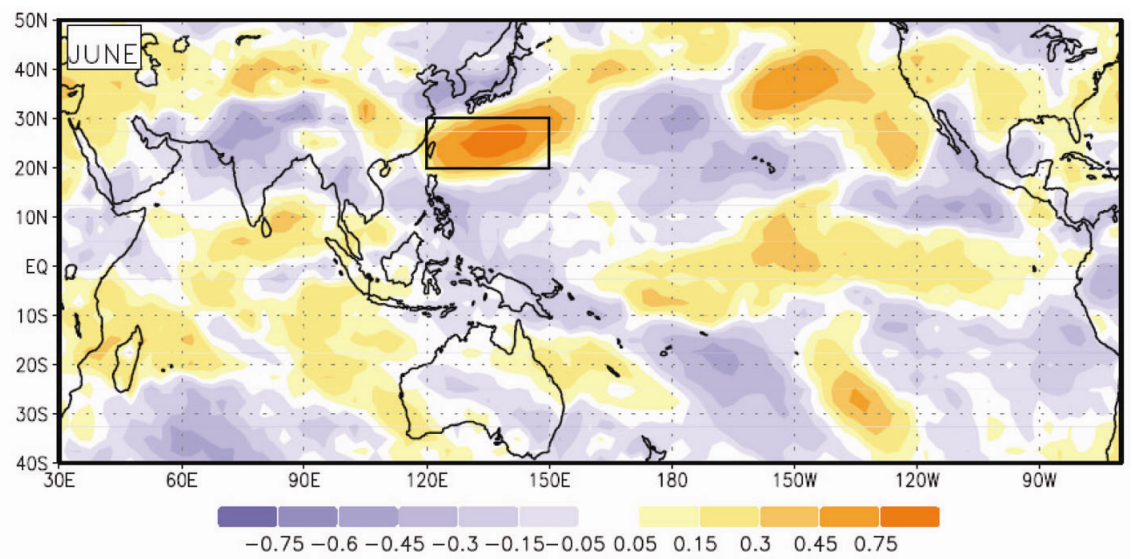

Figure 9. Spatial pattern of the correlation coefficient between OLR and OLR averaged over the NWTP (shown as a box with black boundaries) for June.
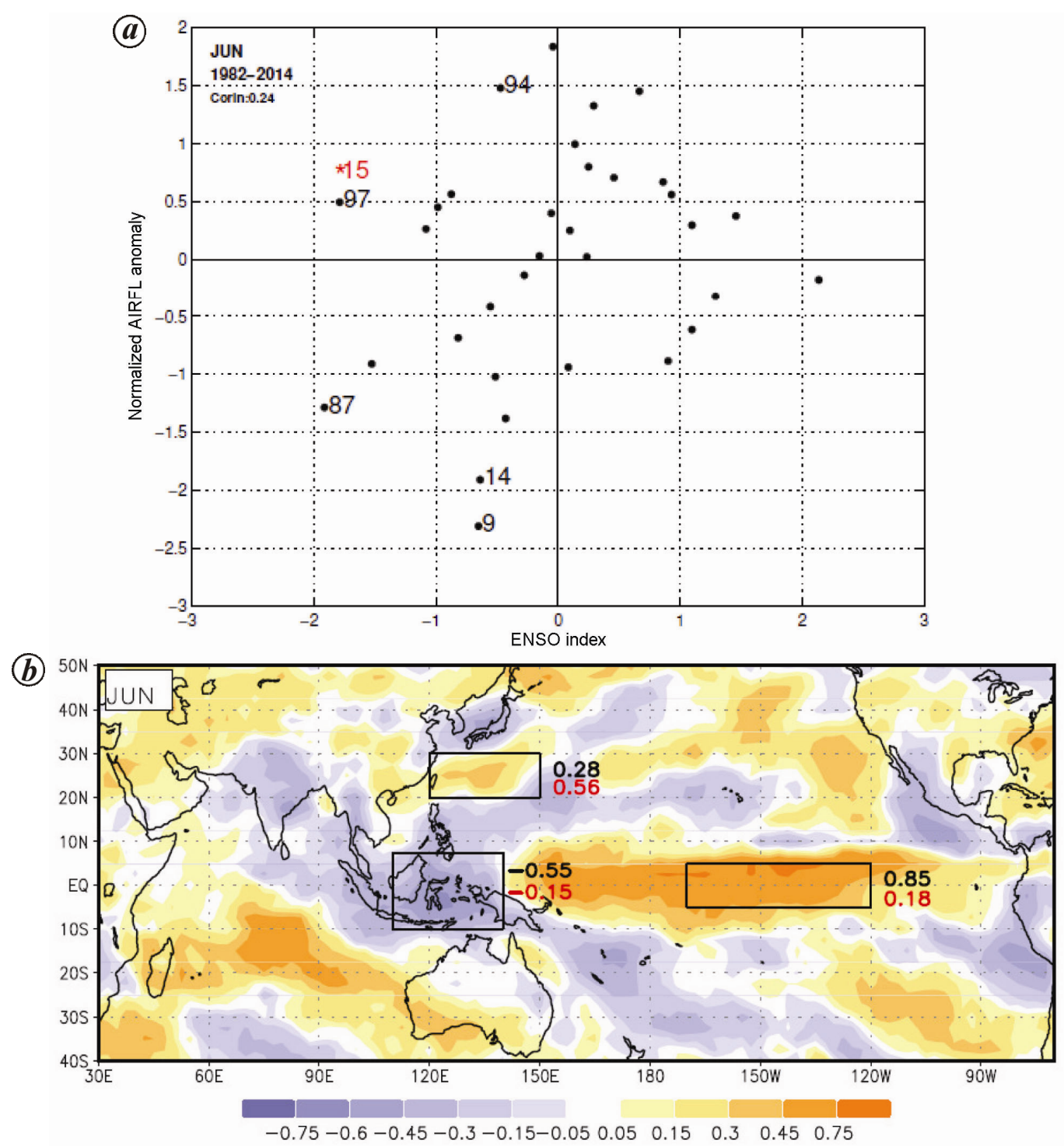

Figure 10. $\boldsymbol{a}$, All-India rainfall (AIRFL) anomaly normalized by standard deviation for June is plotted against ENSO index and the correlation coefficient for 1982-2014 is also shown. $\boldsymbol{b}$, Spatial pattern of the correlation coefficient between the ENSO index and OLR for June. Values indicated near the boxes are the correlation coefficients between OLR averaged over the respective box and ENSO index (black)/all-India rainfall (red). 


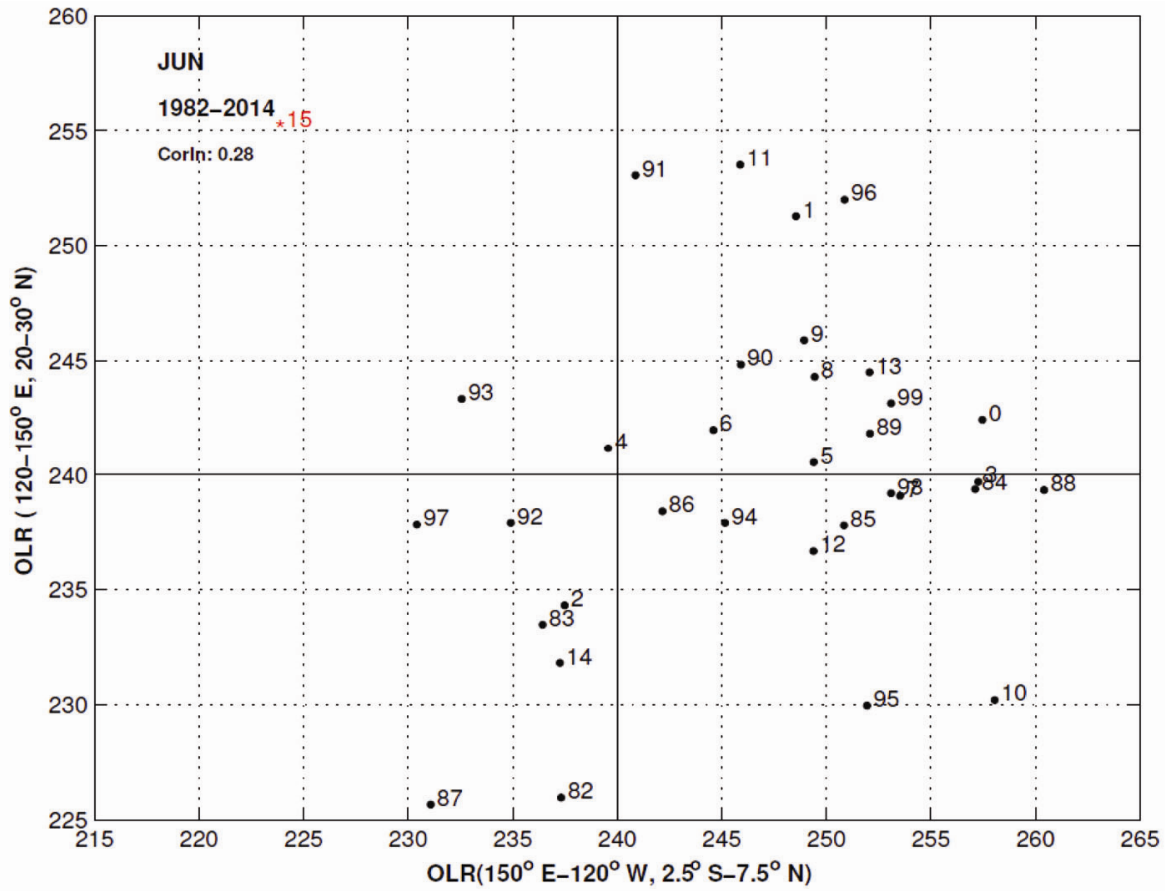

Figure 11. OLR averaged over the NWTP is plotted against the OLR averaged over the equatorial central Pacific $\left(150^{\circ} \mathrm{E}-120^{\circ} \mathrm{W}, 2.5^{\circ} \mathrm{S}-7.5^{\circ} \mathrm{N}\right)$ for June and the correlation coefficient for $1982-2014$ is also shown.
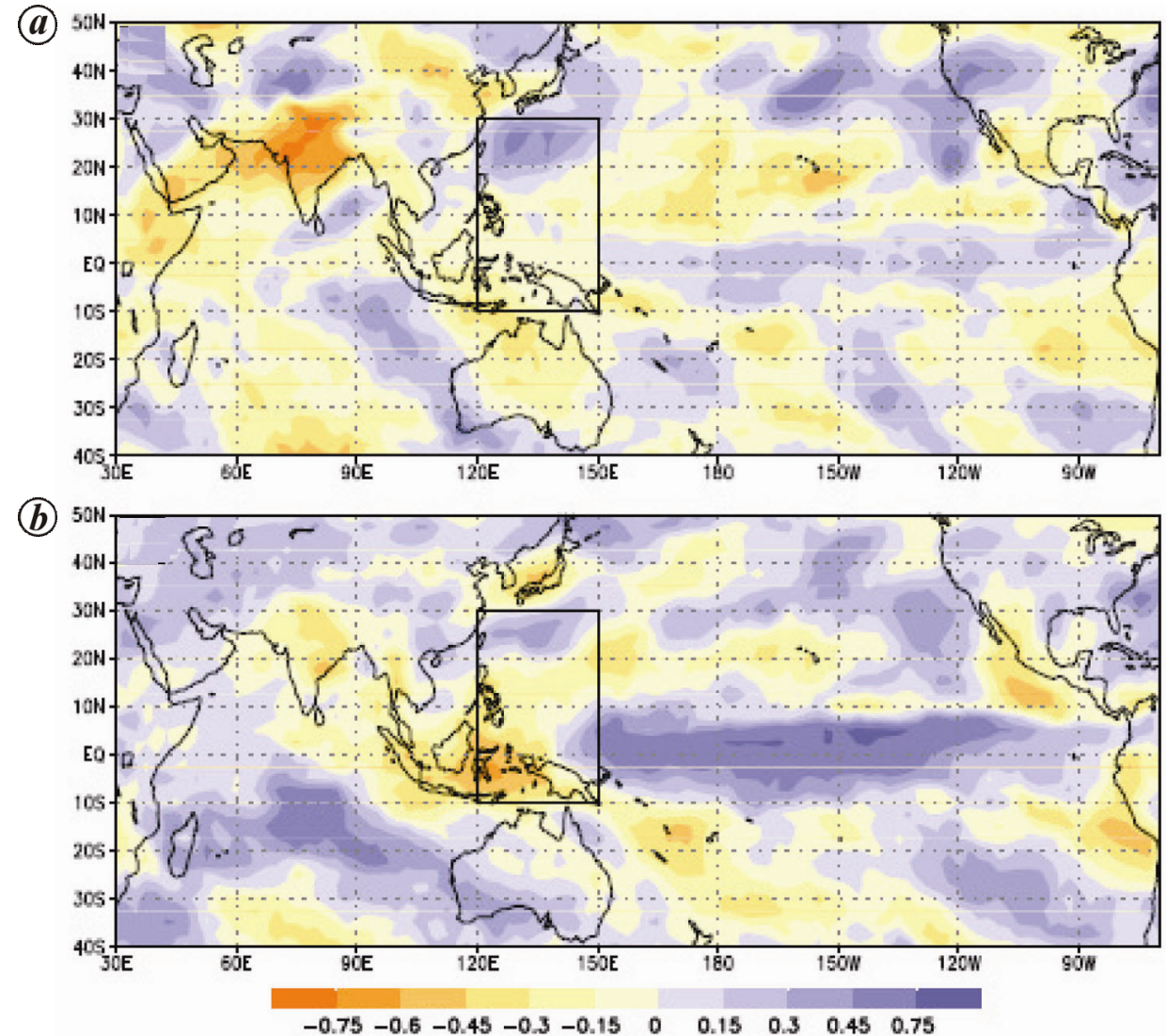

Figure 12. Spatial pattern of the correlation coefficients between OLR and (a) all-India rainfall and (b) ENSO index for June. Period considered for the calculation of correlation coefficients is $1982-2014$. Pattern correlation between the regions shown inside the boxes is 0.7 . 
extending from $10^{\circ} \mathrm{S}$ to $30^{\circ} \mathrm{N}$ associated with ENSO, is found to be unfavourable for rainfall over the Indian region in June, with a pattern correlation of 0.7 (Figure 12). This supports our suggestion that the impact of ENSO over the Indian rainfall in June is via the impact on convection over the West Pacific.

\section{Summary and discussion}

We experienced a striking contrast between the 2014 summer monsoon season and the 2015 season in the rainfall over the Indian region in June, with a massive deficit of about $42 \%$ in June 2014 and an excess of $16 \%$ in June 2015. The large deficit in June 2014 contributed substantially to the drought in that monsoon season. The monsoon season of 2015 , with a deficit of $14 \%$, in the ISMR, has not turned out to be a severe drought despite large deficit in July, August and September, because of the above normal rainfall in June. Clearly, it is important to understand the variability of the all-India rainfall in June.

We have shown that the convection over the northwestern parts of the tropical Pacific (NWTP) plays a very important role in determining this variability. The large deficit in June rainfall in 2014 was associated with enhanced convection over the NWTP. In June 2015, convection over the NWTP was suppressed and the country received above normal rainfall. We find that enhanced convection over NWTP in June is associated with southward migration of the subtropical jet over the West Pacific. Our comparison of the variation of the low OLR belt over 130E with the pre-meiyu and meiyu events identified by Ho and Wang ${ }^{32}$ suggests that the pre-meiyu front around $25^{\circ} \mathrm{N}$ is associated with enhanced convection over the NWTP. This realationship needs to be investigated further.

Since deficit rainfall was predicted for both the monsoon seasons in anticipation of an El Niño, it is important to also address the question of whether the deficit in June 2014 could be attributed to El Niño, and if so, why with a stronger El Niño, the rainfall in June 2015 was above normal. In this study, we have also addressed this problem. We have shown that there is a high propensity for enhancement of convection over NWTP in June, when there is enhancement of convection over the equatorial central Pacific in association with an El Niño, and suggested that the impact of El Niño on the rainfall over the Indian region is via enhancement of convection over NWTP. This occurred in June 2014 and hence we suggest that the massive deficit in the rainfall of June 2014 could be primarily attributed to El Niño. Our finding of high propensity of enhanced convection over NWTP during El Niño events, which is associated with southward migration of the subtropical jet, supports the result of a theoretical study by Shaman and Tziperman ${ }^{35}$, which showed that the subtropical jet migrates southwards over the West
Pacific as a response to enhanced mid-tropospheric heating over the equatorial central Pacific associated with an El Niño event. As this study ${ }^{35}$ is based on a simple barotropic model, it is necessary that this hypothesis be tested using a robust general circulation model, so that the response the Indian monsoon to different El Niño events can be better understood.

We have noted that despite enhancement of the convection over the equatorial central Pacific in association with El Niño, southward migration of the subtropical jet and the enhancement of convection over NWTP does not always occur, as seen in the case of June 2015. Also such enhancement of convection over NWTP does occur sometimes in the absence of El Niño as well, as in 1995 and 2010. It is thus important to unravel the factors besides ENSO that determine the variation of convection over NWTP so as to be able to predict the convection anomaly in June and hence anticipate the rainfall anomaly over the Indian region. With the large overlap between region under the sway of the EASM and NWTP, and the links between the variability of the convection over the NWTP and the variation of EASM and pre-meiyu and meiyu events, we hope to gain insight into these problems in collaboration with EASM experts in near future.

We have also shown that in addition to the variation of convection over NWTP, that over SEEIO contributes significantly to the variability of June rainfall. We find that most of the large deficit (excess) in all-India rainfall in the month of June are associated with enhanced (suppressed) convection over either or both of these regions. As the convection over the SEEIO is closely linked to the phase of EQUINOO, the unfavourable (favourable) phase of EQUINOO contributed to this deficit (excess) rainfall over India in June 2014 (2015). On the other hand, in the deficit June 2012 rainfall, the unfavourable convection anomaly over NWTP was mitigated to a certain extent by a favourable EQUINOO phase while in June 2013, the favourable impact of the convection anomaly of NWTP overwhelmed the unfavourable impact of the negative phase of EQUINOO and the rainfall was above normal. This brings out again the importance of prediction of the phase of EQUINOO and in particular, the OLR anomaly over the eastern pole for prediction of rainfall over the Indian region.

1. Sikka, D. R., Some aspects of the large scale fluctuations of summer monsoon rainfall over India in relation to fluctuations in the planetary and regional scale circulation parameters. Proc. Indian Acad. Sci. (Earth Planet. Sci.), 1980, 89, 179-195.

2. Pant, G. B. and Parthasarathy, B., Some aspects of an association between the southern oscillation and Indian summer monsoon. Arch. Meteorol. Geophys. Bioklimatol., 1981, 1329, 245-252.

3. Rasmusson, E. M. and Carpenter, T. H., The relationship between eastern equatorial Pacific sea surface temperature and rainfall over India and Sri Lanka. Mon. Weather Rev., 1983, 111, 517-528.

4. Rasmussen, E. M. and Carpenter, T. H., Variations in tropical sea surface temperature and surface wind fields associated with the 


\section{RESEARCH ARTICLES}

Southern Oscillation/El Niño. Mon. Weather Rev., 1982, 110 354-384.

5. Philander, S. G. H., El Niño, La Niña and the Southern Oscillation, Academic Press, New York, 1990, p. 293.

6. Sarachik, S. Edward and Cane. Mark The El Niño and southern oscillation phenomenon, 2010, Cambridge University Press, Cambridge, UK, p. 384.

7. ENSO: Recent Evolution, Current Status and Predictions, update prepared by Climate Prediction Center/NCEP 19 May 2014.

8. Long Range Forecast Update for 2014 Southwest Monsoon Rainfall, 9 June 2014, Earth System Science Organization (ESSO), Ministry of Earth Sciences (MoES), India Meteorological Department.

9. ENSO: Recent Evolution, Current Status and Predictions, update prepared by Climate Prediction Center/NCEP 26 May 2015.

10. Long Range Forecast Update for 2015 Southwest Monsoon Rainfall, 2 June 2015, Earth System Science Organization (ESSO), Ministry of Earth Sciences (MoES), India Meteorological Department.

11. Francis, P. A. and Gadgil, Sulochana, The aberrant behaviour of the Indian monsoon in June 2009. Curr. Sci., 2009, 97(9), 12911295.

12. Francis, P. A. and Sulochana Gadgil, Towards understanding the unusual Indian monsoon in 2009. J. Earth Syst. Sci., 2010, 119(4), 397-415.

13. Gadgil, Sulochana, Vinayachandran, P. N. and Francis, P. A., Droughts of the Indian summer monsoon: Role of clouds over the Indian Ocean. Curr. Sci., 2003, 85, 1713-1719.

14. Gadgil, Sulochana, Vinaychandran, P. N., Francis, P. A. and Gadgil, Siddhartha, Extremes of Indian summer monsoon rainfall, ENSO, equatorial Indian Ocean Oscillation. Geophys. Res. Lett., 2004, 31; doi: 10.1029/2004GL019733.

15. Sajani Surendran, Sulochana Gadgil, Francis P. A. and Rajeevan M., Prediction of Indian rainfall during the summer monsoon season on the basis of links with equatorial Pacific and Indian Ocean climate indices. Environ. Res. Lett., 2015, 10, 094004.

16. Krishnan, R. and Sugi, M., Baiu rainfall variability and its monsoon teleconnections, J. Met. Soc., 2001, 79, 851-860.

17. Kripalani, R. H. and Ashwini Kulkarni, Monsoon rainfall variations and teleconnections with rainfall variation over south and east Asia. Int. J. Climatol., 2001, 21, 603-616.

18. Gadgil, Sulochana, The Indian Monsoon and its variability. Annu. Rev. Earth. Planet. Sci., 2003, 31, 429-467.

19. Ding, Y. and Sikka, D. R., Synoptic Systems and Weather in the Asian Monsoon (ed. Wang, B.), Praxis, Chichester, UK, 2005, pp. 131-202.

20. Krishnamurti, T. N. and Ardanuy, P., The 10 to 20 day westward propagating mode and breaks in the monsoon. Tellus, 1980, 32, 15-26.

21. Rao, Y. P., Southwest Monsoon, Meteorological Monograph, Synoptic Meteorology No. 1/1976, India Meteorological Department, 1976.

22. Joseph, P. V., Onset, advance and withdrawal of monsoon, Monsoon Monograph Vol. 1 (eds Tyagi, A., Asnani, G. C., De, U. S.,
Hatwar, H. R. and Mazumdar, A. B.), India Meteorological Department, 2012.

23. Khole, M., Meteorological conditions associated with very sluggish advance of Indian summer monsoon in 2002. Mausam, 2009, 60, 51-60.

24. Bansod, S. D., Singh, S. V. and Kripalani, R. H., The relationship of monsoon onset with subsequent rainfall over India. Int. J. Climatol., 1991, 11(7), 809-817.

25. Liebmann, B. and Smith, C. A., Description of a complete outgoing longwave radiation dataset. Bull. Am. Meteorol. Soc., 1996, 77, 1275-1277.

26. Kalnay, E. et al., The NCEP/NCAR 40-year reanalysis project. Bull. Am. Meteorol. Soc., 1996, 2, 437-471.

27. Pattanaik, D. R. and Rajeevan, M., North-west Pacific tropical cyclone activity and July rainfall over India. Meteorol. Atmos. Phys., 2006; doi: 10.1007/s00703-006-0193-0 (and references therein)

28. Tao, S. and Chen, L., A review of recent research on the East Asian summer monsoon in China. In Monsoon Meteorology (eds Chang, C. P. and Krishnamurti, T. N.), Oxford University Press, Oxford, UK, 1987, pp. 60-92.

29. Wang, B. and $\mathrm{Xu}, \mathrm{X}$., Northern hemisphere summer monsoon singularities and climatological intraseasonal oscillation. J. Climate, 1997, 10, 1071-1085.

30. Wu, R. and Wang, B., Multi-stage onset of the summer monsoon over the western North Pacific. Clim. Dynam., 2000, 17, 277-289.

31. Yim, So-Young, Bin Wang and Xing, Wen, Prediction of early summer rainfall over South China by a physical-empirical model. Clim. Dyn., 2014, 43, 1883-1891; doi: 10.1007/s00382-0132014-3.

32. Ho Lin and Wang, B., The time-space structure of the AsianPacific summer monsoon: a fast annual cycle view. J. Climate, 2002, 15(15), 2001-2019.

33. Chen, G. T. J. and Chang, C. P., The structure and vorticity budget of an early summer monsoon trough (Mei-Yu) over southeastern China and Japan. Mon. Weather Rev., 1980, 108, 942-953.

34. Ding, Y. H., Monsoons over China, Kluwer Academic Publisher, Dordrecht, Boston and London, 1994, p. 419.

35. Shaman, J. and Tziperman, E., Summertime ENSO-North African-Asian Jet teleconnection and implications for the Indian monsoons. Geophys. Res. Lett., 2007, 34, L11702, doi: 10.1029/ 2006 GL029143.

36. IMD, Monsoon 2014, a report, 2015, IMD Met. Monograph ESSO/IMD/Synoptic Met/01, 2015.

ACKNOWLEDGEMENTS. I thank Profs J. Srinivasan, Mark Cane and Steve Zebiak for stimulating discussions. Financial support from the HOOFS programme of ESSO-INCOIS, Ministry of Earth Sciences, is acknowledged.

Received 31 August 2015; revised accepted 30 December 2015

doi: $10.18520 / \mathrm{cs} / \mathrm{v} 110 / \mathrm{i6} / 1010-1022$ 